\title{
Obstacles to Sustaining Diversity: Historical Context and Current Experiences of Underrepresented Minority Women and Men in Sociology and Economics
}

\author{
Roberta M. Spalter-Roth
}

check for

updates

Citation: Spalter-Roth, R.M. Obstacles to Sustaining Diversity: Historical Context and Current Experiences of Underrepresented Minority Women and Men in Sociology and Economics. Sustainability 2021, 13, 11858. https://doi.org/10.3390/su132111858

Academic Editors: Sandra L. Hanson and Enrique S. Pumar

Received: 17 August 2021

Accepted: 30 September 2021

Published: 27 October 2021

Publisher's Note: MDPI stays neutral with regard to jurisdictional claims in published maps and institutional affiliations.

Copyright: (C) 2021 by the author. Licensee MDPI, Basel, Switzerland. This article is an open access article distributed under the terms and conditions of the Creative Commons Attribution (CC BY) license (https:/ / creativecommons.org/licenses/by/ $4.0 /)$.
Center for Social Science Research, George Mason University, Fairfax, VA 22030, USA; rspalter@gmu.edu

\begin{abstract}
White men predominate in the top ranks of the professorate, but recent efforts have attempted to decrease inequality and increase diversity in the academy by hiring more faculty, especially women of color. Have equality and diversity efforts worked or has negative departmental climate limited efforts to make diversity sustainable? Despite the long history of and many contributions by women of color (URC) as public intellectuals, activists, and founders of organizations to promote Blacks and Latino/a people, we find that much of their work is still marginalized and is not viewed as legitimate science. This treatment may lessen the ability to increase equality and sustain diversity in academic institutions. The paper tests whether URC women scholars are still experiencing inequalities in comparison to their male peers of color in two disciplines, that of sociology and economics. We include these two disciplines because of similarities in origin and of topics. First, we hypothesize that women of color have significantly more negative experiences in sociology and economics departments than do men of color, when other conditions are held constant. Second, we hypothesize that structural conditions, are related to experiential outcomes for these scholars. Third, we hypothesize that participation in minority-oriented organizations improves women of color's experiences. Fourth, we hypothesize that interacting gender with participation in minority-oriented organizations, significantly improves women of color's situation. The study results show that women of color continue to experience greater problems of access, marginality, inclusion, and harassment in sociology and economics departments. The sustainable development goals of achieving gender equality and increase educational opportunities cannot be achieve without addressing these inequities and inclusion issues.
\end{abstract}

Keywords: women of color; men of color; equality; diversity; sustainability

\section{Purpose of the Paper}

Gender equality is one of the 17 goals that the United Nations lists as important for social sustainability (https://www.un.org/sustainability accessed on 10 April 2021). We ask if this goal of gender equality as part of diversity efforts have become sustainable in institutions of higher education in the United States (U.S.). There is still a paucity of information and analysis on the sustainability of women's participation in the academy and especially of women of color. It is the purpose of this paper to fill this gap by examining both the history of the exclusion and marginalization of Black and Latinix women prior to and including participation in institutions of higher education in the U.S. The U.S. was chosen because of the relatively wealth of data and because the author was funded to do research based on the U.S. model.

Currently, White men predominate in the top ranks of the U.S. professorate [1] but recent efforts attempt to decrease inequality and increase diversity in the academy by hiring more faculty, especially women of color. We examine negative departmental climates and suggest that they may limit efforts to make equality and diversity efforts sustainable? Despite the long history of and many contributions by under-represented women of color (URM) as public intellectuals, activists, and founders of organizations to promote Blacks 
and Latino/a people, much of their academic work is still marginalized and is not viewed as legitimate science [2,3]. This treatment may lessen the ability to increase equality and sustain diversity in academic institutions. The paper tests whether URM women scholars in sociology and economics are still experiencing inequalities in comparison to their male peers of color in these two disciplines. We briefly examine these historical inequalities and then examine current experiences in sociology and economics departments between men and women of color. We focus these two disciplines because of similarities in origin and of topics. The data presented here show that both women and men of color have negative experiences, but women of color experience significantly more. We suggest that these differences follow the historical pattern experienced by URM women outside as well as inside the academy. We conclude that diversity will not be sustainable in universities unless these negative conditions are overcome.

The conceptual framework for this paper is an intersectional one-a method that allows individuals, especially women, to have more than one source of oppression [4-8]. Intersectionality is a theory that demonstrates how social categories such as race, class, and gender interact and cause overlapping and interdependent systems of oppression, discrimination, and disadvantage $[7,8]$. Thus, race and gender are not mutually exclusive social categories. For example, Black women face their own type of discrimination.in comparison to Black men. Yet all too often, "Black" has been equated with Black men and "woman" was equated with White women. Black (and Latina) women were an invisible group whose existence and needs were ignored. The title of the groundbreaking anthology, All the Women are White, All the Blacks are Men, But Some of us are Brave edited by Hull, Scott, and Smith [9] illustrates the conditions behind the need for an intersectional analysis to understand Black women's oppression.

As a result of their participation in liberation movements, as well as their academic and professional experiences, it is near impossible for Black women and Latinas to separate race from class and sex oppression, because they experienced them simultaneously. Black feminist thought fosters and represents a fundamental paradigmatic shift in how we think about oppression $[4,6]$. By embracing a paradigm of race, class, and gender as interlocking systems of oppression, Black feminist thought reconceptualizes the social relations of domination and resistance [4,6,7,9-12]. Without the concept of intersectionality, we would be limited to comparing all women or all minorities, as is done in much survey analysis. In this analysis we compare Under-Represented Minority women to URM men, capturing both sets of identities at once. This paper is unique in the context of gender literature in that it provides current experiences of women of color in academia as a continuation of their historical experiences.

While the paper provides specific histories of Black and Latinix women's entry into academia in the literature review and recognizes their distinct experiences, we combine these racial/ethnic identities into the category of Under-represented Minority (URM) women and men in the statistical analysis. We combine them on the one hand, because cell sizes, especially for economists, would be too small for reliable analysis. On the other hand, both groups of women have common purposes to overcome marginalization and discrimination, according to Dr. Shirley Malcolm, the Director of Education and Human Resources at the American Academy for the Advancement of Science. The paper tests whether URM women scholars are still experiencing inequalities in comparison to their male peers of color in two disciplines through descriptive, multi-variate and in-depth interviews.

We first discuss why we choose economics and sociology as two comparative disciplines. We then present a brief history of the participation of Black and Latinx women in both academic and non-academic organizations from the late 19th century through the current period. The historical examples provide the grounding for the analysis of survey data that follows. Next, we present the study's methodology, including a description of the survey, the variables included, and the development of the categories of analysis. We go on to test the study's four hypotheses and present the results. 


\subsection{Why Economics and Sociology?}

We include both economists and sociologists in this study for several reasons. First, they have a common heritage. Not only did many early sociologists receive their formal training as economists (e.g., Weber, Veblen, Small, and Giddings), but from about 1880 1906, sociology existed as a sub-field within economics [13]. This intimate interdisciplinary relationship is further illustrated by the origins of the American Sociological Association (ASA) which was launched during an American Economic Association (AEA) meeting in 1905 [14]. During the 19th and early 20th century, cross-disciplinary analysis of the economic and social lives of URMs began, in opposition to widespread disciplinary beliefs that Blacks were biologically and cognitively inferior and that their work was only "Negroes studying Negroes" $[15,16]$. Many URM scholars attribute the beginnings of social science in both economics and sociology to W.E.B. DuBois who is considered as an intellectual progenitor of empirical and policy-oriented sociology and economics in the United States $[17,18]$.

A second reason for studying these disciplines together is that women of color experienced a common heritage of efforts to constrain their academic participation, including preferential admissions policies benefiting White males and tracking women of color into segregated academic programs such as home economics and domestic work $[15,19]$. Third, there are similarities in definitions and topic areas such as human and social capital as well as newer concepts including feminist intersectional theory. The paradigmatic challenges posed by feminist theory to the epistemic cultures of both disciplines can be the basis for continued interdisciplinary work. Forth, a relatively new framework, that of stratification economics in the U.S. analyzes social stratification, a concept that is central to sociology, providing common ground between the disciplines [20]. On a more practical level, we combine sociologists and economists, because of the relatively small sample sizes we have in our unique dataset (especially for economists) and because of the funding interests of the National Science Foundation (NSF). Finally, scholars in sociology and in stratification economics focus on the study of inequalities and advocate for its reduction.

However, there are admittedly clear-cut differences between the disciplines in terms of gender and racial equality. Sociology has the second highest participation of women (exceeded only by psychology) and economics has among the smallest proportion of women in the social sciences. The participation of women of color is substantially lower than for White women. Only 0.9 percent of graduate students in economics are Black and 1.1 percent are Latina [21]. In contrast, 7.8 percent of graduate students in sociology are Black and 6.7 percent are Latinx women [21]. Despite the differences in their respective shares of each discipline, women of color in both disciplines face inequalities such as harassment, lack of resources, and lack of legitimacy, as we will see. Most recently, there has been increased evidence about sexual harassment of women in economics [22,23].

\subsection{Historical Overview}

Throughout a more than one-hundred-year history, traditionally underrepresented minority URM continue to have problems of access, inclusion, and harassment in patriarchal institutions, including social movements and social institutions such as higher education where White men predominate [1,3]. There has been a history of efforts by White scholars, and sometimes their URM male colleagues, to hinder women of color's inclusion and the legitimacy of their intellectual work [2], [24-26]. We compare experiences between men and women of color historically, and currently in academic departments. The results suggest the importance of using intersectionality as a method, because that there are unequal experiences, among members of this group, with URM women seemingly considered as a "second sex" in post-slavery periods.

The history of Black women and Chicanas (later labelled Latinas to include those with a Latin American background as well as those with a Mexican background) reveals a gendered division of labor over time that sometimes resulted in conflicts with their male compatriots, as well as with White women's organizations [27]. The historical overview 
of gender provides a context for understanding the study results showing a continuation of gender inequality and the experiences that sustain it. Without this history, the results would be a-contextual without an understanding of the lack of diversity over time.

\subsubsection{The Early Period (1880-1920)}

During the late 19th and early 20th century, the marginalization of Black women in the academy was even greater than that of Black men. Educated Black women were not encouraged to participate in male professions such as the Black church which was dominated by Black male charismatic leaders [28]. Yet, a group of Black female leaders including Mary McCloud Bethune, Anna Julia Cooper, Mary Church Terrell, Fannie Jackson Coppin, and Ida B. Wells began a range of racial-uplift activities. These initiatives included education, social welfare, healthcare, and anti-lynching efforts that were founded in the face of racial and sexual violence. Although they were, perhaps, among the first public intellectuals, their arena was not higher education, but morally oriented work, done within the confines of the "cult of true womanhood" that emphasized women's role within the private sphere in contrast to men's role in the public sphere. In contrast to Black males' charismatic leadership, Black women leaders were expected to support motherhood and educate the next generation [28].

Luziris [29] argues that Chicana history should include the women attached to the Mexican Revolution. As with the Black women, they founded organizations to help uplift their people. Women such as Jovita Gonzalez, Jovita Idar, and Leonor Villegaz Magnon were teachers, journalists, public intellectuals, and founders of organizations such as the League of Mexican Women devoted to offering free education to Mexican children and La Cruz Blanca a relief organization during the Mexican American War (Jones, 2012 Texas State Historical Association). The mission of these women's organizations was, as with those of Black women, to uplift "la raza."

\subsubsection{The Middle Period (1920-1960)}

Black women continued to work in organizations that promised racial uplift (Giddings 1985). During this period, organizations were devoted to racial or gender empowerment, but not both. This often resulted in women members of color being subject to gender discrimination within these organizations (Black History and Women Timeline. https: / www. thoughtco.com/african-american-womens-history-timeline-1990-1999-3528314. Accessed on 10 April 2021)

By the 1950s, Black women were accepted at Northern, Mid-Western and Western public universities. However, as Black women attempted to join sociology and economics departments, they were often siphoned off into the growing fields of home economics, social work, and education [30,31]. Over the next two decades, gender and racial composition (especially the inclusion of White women) shifted dramatically on coeducational university campuses. During this period, URM women and men increasingly fought and ultimately found academic employment in the disciplines despite the lack of professional recognition and rewards for their work [30].

Unlike, Blacks who had been in the U.S. under the burden of slavery and Jim Crow, since the country's founding, large numbers of Latinx people did not migrate to the U.S. until the 1970s, although some were recruited to work in orchards of the U.S., starting in the 1940s. Puerto Rican women, who are citizens of the United States, migrated earlier. Mexican-American women participated in strikes and the development of community organizations during this period that sought strategies to improve their situation and that of their families [31,32]. These efforts focused on working class Latinx people. Some Chicanas reached prominence in their roles as union organizers, although there were still strong efforts to confine their activities to traditional roles within the family [26]. 


\subsubsection{The Turbulent 1960s and 1970s}

Starting in the 1960s and 1970s, racial and ethnic liberation movements gained strength and notoriety, while facing backlash and violence. The nation's first Black Studies Program was established at San Francisco State University having faced considerable resistance from administrators [4]. Black women and Latinx women were deeply engaged in these liberation movements, often out-numbering men. Yet, these movements often reinforced a gendered division of labor and marginalized gender critiques $[9,21,25,33]$.

In addition, Black and Latinx women who participated in the feminist movement during the 1960s were often met with racism by White women $[33,34]$ that generally took the form of exclusion. Black women or Latinas were not invited to participate on conference panels that were not specifically about Black or Third World women, nor were there classes devoted specifically to the study of women of colors' history [8]. In most early second wave women's movement writings, the experiences of White, middle-class women were described as universal "women's experiences," ignoring the differences of Black and White women's experiences due to race and class [33].

Over time, women of color have questioned the gendered hierarchy in institutions, organizations, and social movements for Black and Latinx women [9,21,25,35]. By embracing a paradigm of race, class, and gender as interlocking systems of oppression, Black feminist thought reconceptualized the social relations of domination and resistance $[7,9,35]$. Likewise, the Chicana or Latina feminist movement grew out of the patriarchy in the Chicano movement and the unequal treatment of women [36]. Chicana activists were chastised for not following the norms of Chicana womanhood and were expected to conform to patriarchal norms of unequal power in the family [37-39]. Chicana activists and scholars criticized the inability of the mainstream Chicano nationalist movements to address sexism and misogyny. Simultaneously, they renounced the mainstream Second Wave feminist movement for its inability to include racism and classism in their politics [40,41].

\subsubsection{Beyond the 1970's}

Since the 1970s and 1980s feminist economists and sociologists developed organizations that studied unequal treatment of women and attempted to sustain changes in the two disciplines. These included CSWEP (Committee on the Status of Women in the Economics Profession), one of the standing committees of the American Economic Association), IAFFE (International Association for Feminists in Economics), SWS (Sociologists for Women in Society), the American Sociological Association's section on Sex and Gender, and the Committee on the Status of Women in Sociology. Many women in these organizations see their mission as sustaining and strengthening their role in the scholarly community. In addition, some have created journals that provided a space for their work such as Gender and Society and Feminist Economics. Yet, these organizations and journals do not always focus on the Special Issues of women of color in an inclusive way.

URM feminists in these two disciplines made a solid contribution with studies of immigration, labor market and occupational inequalities, family studies, and health and welfare, along with pointing out androcentric and racist biases within their disciplines. Yet, despite continued efforts to raise their status by following academic norms, those at historically White institutions often face informal and structural barriers to overcoming inequalities [23].

\section{The Study}

The purpose of the study is to test a series of hypotheses.

\subsection{Hypothesis}

First, we hypothesize that women of color have significantly more negative experiences in sociology and economics departments than do men of color, when other conditions are held constant. We suggest that differences between women and men follow the historical pattern experienced by women of color over-time. Second, we hypothesize that 
structural conditions, are related to experiential outcomes. By structural conditions, we mean stratified institutional relationships. For example, graduating from a research extensive institution or teaching at such an institution may command more respect than other institutions, and may mitigate negative experiences such as a lack of legitimation that often experienced by URM scholars [1]. (In 2015, the last year Carnegie updated its classifications, just 115 institutions held R-1 status, seven more than in 2010). Third, we hypothesize that participation in organizations designed for scholars of color in sociology and economics can mitigate negative experiences. Fourth, we hypothesize that when we interact gender with participation in minority-oriented organizations, the interaction significantly improves UTM women's situation. We suggest that their participation in organizations designed to provide spaces for networking and scholarship can have a positive and significant relationship in overcoming negative experiences for women in this study, as did such participation has in the past.

As noted, the methods used to test these hypotheses include descriptive and multivariate analysis and in-depth interviews. The dependent variables in the multivariate regression analysis include race and gender, composite scores from the survey capturing four types of experiences within departments (see discussion below of how scales were created). In addition, we collected unobtrusive or secondary data on structural variables such as institutions of higher education, publications, years in the academy, and participations in disciplinary URM organizations. We chose to start the period covered by the study in 1996 and to end it in 2006. This period would allow PhD graduates eight years (until 2014) to gain tenure, and to obtain the rank of associate professor and eighteen years (until 2014) to obtain a full professorship.

\subsection{The Sample}

We used the following methods to draw the sample:

For the unobtrusive data, the dependent variables were the gaining of tenure and full professorship in eight and 14 years, respectively, after they gained their PhDs. So we used PhD Recipients from 1999-2006 so that by the time we sent the survey all respondents had a chance to obtain tenure, be promoted to associate professor or become a full professor.

To identify a sample of Black and Latinx sociologists who were able to become associate or full professors we used the ASA's Guide to Graduate Departments for every year between 1995 and 2006, we employed a panel of experts to go through the list of $\mathrm{PhD}$ recipients and identify recipients' race/ethnicity and gender. Any confirmed non-URM faculty members were removed from the study. The result is a total of 332 Black and Hispanic academic sociologists.

To identify a sample of Black and Latinx economists, a combination of doctoral dissertation titles and databases corresponding to Ph.D. graduates in the academic years 1995 to 2006 were used. Databases included lists of Black/Latinx economists based on memberships to American Society of Hispanic Economists (ASHE), Diversity Initiative for Tenure in Economics (DITE), and the National Economics Association (NEA), as well as a published list of Black economists by Price and Sharpe [42]. The results include a total of 175 Black and Latino/Latina scholars who are currently academics (It should be noted that the original sample of URM economists and sociologists to whom the survey was administered was collected through non-probability sampling (not random), thus, our sample may not be representative of the population. For further information concerning the study's sample or data collection process, please contact authors).

\subsection{Unobtrusive Data}

The data for the independent variables in the study came from a series of unobtrusive data sources including membership lists, ProQuest dissertation information, curriculum vitae, and web searches through Google, Google Scholar, Academic.edu, and Research Gate. We searched these data sets from 2006 through 2014. Throughout the analysis, we divide institutions of higher education into two types, research extensive institutions 
and non-research extensive institutions because cell sizes for the latter are too small for further breakdowns. This latter category includes non-research extensive PhD-granting institutions, master's-only institutions, and baccalaureate-only institutions. The data collected can be roughly divided into two categories: human and social capital measures. We measure human capital by focusing on factors that are regarded by economists as individually acquired. This notion is heavily influenced by neo-classical economics. In contrast, social capital depends on a set of relations that provide mutual recognition among participants such as networks and organizations to accrue symbolic or material resources [43]. The human capital measures are indicators of social stratification and include variables such as years in academia, current institution of employment, $\mathrm{PhD}$ institution, race/ethnicity, gender, discipline, and average publications. The measure of social capital that we use is participation in a URM oriented section or organization (In sociology the sections include Latino/a Sociology, Racial and Ethnic Minorities, and Race, Gender, and Class In economics the organizations include the National Economic Association (NEA), which promotes the professional lives of minorities within the profession, and the American Society of Hispanic Economists (ASHE). Table 1 presents these variables, the number of responses, and the mean and standard deviation for each variable.

Table 1. Description of Variables in the model.

\begin{tabular}{|c|c|c|c|}
\hline Variable & $N$ & Mean (SD) & Description \\
\hline Sex $(1=$ Female $)$ & 198 & $0.50(0.50)$ & $\begin{array}{l}\text { Self-identified sex of subject (Male or Female)—Dummy variable } \\
\text { coded } 1 \text { if subject is female or } 0 \text { if the subject is male. }\end{array}$ \\
\hline Race (1 = Black) & 198 & $0.55(0.50)$ & $\begin{array}{l}\text { Self-identified race of subject (Black or Hispanic only)_Dummy } \\
\text { variable coded } 1 \text { if subject is Black or } 0 \text { if the subject is Hispanic. }\end{array}$ \\
\hline $\begin{array}{l}\text { Graduated from a } \\
\text { RE Institution }\end{array}$ & 197 & $0.91(0.29)$ & $\begin{array}{l}\text { Carnegie research classification of institution from which the } \\
\text { subject graduated-Dummy variable coded } 1 \text { if the institution is } \\
\text { ranked at the R } 1 \text { level, } 0 \text { otherwise. }\end{array}$ \\
\hline Employed at a RE Institution & 195 & $0.49(0.50)$ & $\begin{array}{l}\text { Carnegie research classification of institution from which the } \\
\text { subject is employed-Dummy variable coded } 1 \text { if the institution is } \\
\text { ranked at the R } 1 \text { level, } 0 \text { otherwise. }\end{array}$ \\
\hline Average Publications Per Year & 195 & $0.92(0.37)$ & $\begin{array}{l}\text { Average number of total peer-reviewed publications per year since } \\
\text { the subject entered graduate school. }\end{array}$ \\
\hline Years in Academia & 185 & $14.18(3.28)$ & $\begin{array}{l}\text { Number of years the subject has been in academia since } \\
\text { first employment. }\end{array}$ \\
\hline Participate in Minority Section & 198 & $0.34(0.47)$ & $\begin{array}{l}\text { Dummy variable coded } 1 \text { if subject has participated in an ASA } \\
\text { minority section (RGC, SREM, Latina/o, DITE, ASHE), } 0 \text { otherwise }\end{array}$ \\
\hline Discipline (1 = Sociology) & 198 & $0.64(0.48)$ & $\begin{array}{l}\text { Dummy variable coded } 1 \text { if subject graduated with their doctoral } \\
\text { degree in sociology or } 0 \text { if the subject graduated with their doctoral } \\
\text { degree in economics. }\end{array}$ \\
\hline
\end{tabular}

\subsection{Interviews and Open-Ended Comments}

Finally, to learn more about how every-day experiences affect the likelihood of maintaining and sustaining diversity, we examined the actual words of Black and Latina sociologists and economists, using open-ended comments from the survey and comments and from 10 in-depth interviews with selected survey participants who indicated their willingness to further discuss their experiences. These interviews were about one hour in length and allowed respondents to elaborate on the survey answers

\section{The Survey}

We tried to capture the daily experiences of URM women compared to URM men within a climate that still favors White men as "ideal" economists and sociologists because their work is viewed as emphasizing objectivity and positivism [44]. To do this, we sent a 
29-question on-line survey of respondents' perceptions of conditions rather than gathering information on actual conditions. To the 507 economists and sociologists in the sample. The Likert scale survey, designed in Qualtrics, a platform for creating, testing, and distributing surveys, went through several iterations, iterations that included collaborations among the research team (The research team included Roberta Spalter-Roth, Jean H. Shin, Jason Smith, Amber Kalb, Kyle Moore, Jermaine Toney, and Ismael Cid-Martinez). Finally, a consultant (an industrial psychologist) conducted validity tests for the questions. The survey was then pretested. After the pretest, emails that included the survey were sent. Qualtrics allowed us to keep tabs on return rates and to send additional emails to non-respondents. Along with the initial distribution of the survey, we conducted five follow-up reminders to increase the response rate. Of the 507 surveys sent, 479 did not bounce back, did not declare themselves as White and/or as working outside academia. Of the 479 useable surveys, there was a $41 \%$ response rate. Ultimately, our sample included 46 Black men $(23 \%), 62$ Black women (31\%), 37 Latinas (19\%), and 53 Latinos $(27 \%)$ respondents.

Sociologists were more likely to respond than economists, and the majority of respondents held the faculty rank of associate professor. Unfortunately, our sample size does not allow for the disaggregation of sociologists and economists. Additionally, the response rate suggests that we have not captured the full population, and therefore, the results may be biased. That said, our sample is unique and provides insights into URM women's experiences compared to men's experiences. Table 2 shows the rank of these faculty members.

Table 2. Intersectionality of URM faculty respondents by rank in percentages.

\begin{tabular}{ccccc}
\hline & Black Men & Black Women & Latinos & Latinas \\
\hline Sociology & & & & \\
\hline Full professor & 33 & 18 & 30 & 21 \\
Associate professor & 54 & 51 & 57 & 64 \\
Assistant professor & 0 & 14 & 13 & 14 \\
Lecturer (full-time) & 4 & 6 & 0 & 0 \\
Lecturer (part-time) & 4 & 0 & 0 & 0 \\
\hline Economics & & & & \\
\hline Full professor & 27 & 36 & 30 & 22 \\
Associate professor & 50 & 54 & 53 & 0 \\
Assistant professor & 9 & 0 & 3 & 0 \\
Lecturer (full-time) & 0 & 0 & 0 & 0 \\
Lecturer (part-time) & 5 & 0 & &
\end{tabular}

\section{Principal Component and Regression Analysis}

To reduce data from the 29-question survey into internally consistent and distinct categories, we conducted a confirmatory principal component analysis (PCA) on survey responses (The purpose of this analysis was to decrease the number of survey questions and to meaningfully categorize them. Amber Kalb, a doctoral candidate at George Mason University is responsible for this analysis). These categories aimed to measure the relative degree to which URM faculty face instances marginality and exclusion in their departments. The PCA was ultimately run on 26 of the 29-question survey, after a reliability test was performed on each survey item. The results produced four components: (1) Aggression or Neglect; (2) Departmental and Institutional Climate: (3) Legitimacy and Affirmation: and (4) Material Support and Resources (see Appendix A Table A1 for the variables in each component). Composite scores based on survey responses were created from the component loadings for each of these variables. The four components were relatively consistent with the concepts used throughout the history section of the paper, such as marginality and legitimacy, and explained 68.1 percent of the total variance in the survey. Furthermore, strong internal scale consistency was determined by the Cronbach's alphas. 
Eigenvalues, variance explained by individual components and scree plot are presented in Appendix A Table A2.

Each composite measure was used as continuous outcome variables in a set of four multiple OLS regression models and an additional four models with interaction effects. The first four models were developed to determine the significance of relationship between gender (female) and faculty's daily experiences in each of the four categories when other predictor variables based on the unobtrusive measures are held constant. The final four models attempt to measure the same relationship while considering the interaction between certain predictor variables on these experiences.

\section{Findings}

The findings reported in this section of the paper indicate a continuation of marginalization and lack of legitimacy faced by women of color in sociology and economics departments.

\section{Descriptive Findings}

The descriptive analysis presented in Table 3, displays a series of significant differences between URM women's and men's daily experiences, with women having more negative experiences than men. For example, when compared to their male colleagues, we find that women are nearly twice as likely to report unequal treatment in recruitment processes, and almost twice as likely to report not receiving resources to help them balance work and family obligations. Over twice as many women report experiencing verbal abuse or ridicule (although the numbers are small). An additional 17 percent of women report failure to legitimize or take their scholarship seriously. These findings support hypothesis 1 that URM women in U.S. departments of sociology and economics have significantly more negative experiences than do URM men.

Table 3. Survey Cross-Tabulations by Gender and Chi-Square Tests of Significance.

\begin{tabular}{|c|c|c|c|c|}
\hline \multirow[b]{2}{*}{ Survey Question } & \multicolumn{4}{|c|}{ Sex } \\
\hline & $N$ & Male & Female & $x^{2}$ \\
\hline $\begin{array}{c}\text { Minority and non-minority faculty in my department receive equal } \\
\text { treatment in the area of recruitment. }\end{array}$ & 192 & $\%$ (count) & $\%$ (count) & $6.828^{* *}$ \\
\hline Strongly/Somewhat Disagree & & $24(23)$ & $42(40)$ & \\
\hline Strongly/Somewhat Agree & & $76(73)$ & $58(56)$ & \\
\hline $\begin{array}{l}\text { Minority and non-minority faculty have equal influence in } \\
\text { department decisions. }\end{array}$ & 193 & & & $4.836^{*}$ \\
\hline Strongly/Somewhat Disagree & & $28(27)$ & $43(42)$ & \\
\hline Strongly/Somewhat Agree & & $72(69)$ & $57(55)$ & \\
\hline I have a desirable balance between teaching, research, and service & 196 & & & $8.218^{* *}$ \\
\hline Strongly/Somewhat Disagree & & $36(35)$ & $56(55)$ & \\
\hline Strongly/Somewhat Agree & & $64(63)$ & $44(43)$ & \\
\hline I have adequate resources to carry out my research. & 194 & & & $7.582^{* *}$ \\
\hline Strongly/Somewhat Disagree & & $35(34)$ & $55(54)$ & \\
\hline Strongly/Somewhat Agree & & $65(62)$ & $45(44)$ & \\
\hline $\begin{array}{l}\text { I am given resources to help me balance my work and my family } \\
\text { obligations. }\end{array}$ & 195 & & & $16.682 * *$ \\
\hline Strongly/Somewhat Disagree & & $33(32)$ & $62(60)$ & \\
\hline Strongly/Somewhat Agree & & $67(66)$ & $38(37)$ & \\
\hline $\begin{array}{c}\text { I have had to work harder than my colleagues do to be perceived as a } \\
\text { legitimate scholar. }\end{array}$ & 193 & & & $9.027 * *$ \\
\hline Strongly/Somewhat Disagree & & $50(48)$ & $29(28)$ & \\
\hline Strongly/Somewhat Agree & & $50(48)$ & $71(69)$ & \\
\hline Please report the frequency: & & & & \\
\hline
\end{tabular}


Table 3. Cont

\begin{tabular}{|c|c|c|c|c|}
\hline \multirow[b]{2}{*}{ Survey Question } & \multicolumn{4}{|c|}{ Sex } \\
\hline & $N$ & Male & Female & $x^{2}$ \\
\hline Verbal abuse or ridicule & 194 & & & $5.390 *$ \\
\hline Often/Sometimes & & $9(9)$ & $21(21)$ & \\
\hline Rarely/Never & & $91(87)$ & $79(77)$ & \\
\hline Failure to legitimize or take seriously your scholarship & 192 & & & $5.959 *$ \\
\hline Often/Sometimes & & $30(28)$ & $47(46)$ & \\
\hline Rarely/Never & & $70(68)$ & $53(52)$ & \\
\hline Extra scrutiny with regard to teaching and service & 193 & & & 4.230 * \\
\hline Often/Sometimes & & $23(22)$ & $37(36)$ & \\
\hline Rarely/Never & & $77(73)$ & $63(62)$ & \\
\hline
\end{tabular}

${ }^{*}=p<0.05 ;{ }^{* *}=p<0.01$.

URM men have negative experiences as well. It may be that men are more reluctant to report negative experiences than women. However, none of the cases indicate that these men had significantly worse experiences, on average, than their female colleagues, although in some cases their experiences are just as damaging. For example, equal percentages (48 percent) of URM men and women report that they do not spend time with other faculty members in their departments suggesting that they do not have the potential for coauthoring or other networking activities and, therefore diversity is less likely to be sustained because URM academics have less opportunity to participate in publishable research. While we do not measure who is the source of grievances, they may be at the hands of White male and White female faculty and administrators. Eyeballing disciplinary differences, it appears that sociologists feel more negatively about their treatment than do economists. This is a surprising finding, especially given the larger share of women in sociology, and their greater participation in the discipline, and the topic areas of concentration. According to Reskin and Roos [45], women moved disproportionally into sociology because of the reflection of topic areas (e.g., gender; family; race, class and gender, work and occupations, social status, discrimination) with their own lives and interests and because men had other opportunities. This may not be the case for economists. For sociologists gender inequalities as a major research area and there are significantly more of them to complain to one another (Since there are relatively few economists who participated in the survey, a comparison between sociologists and economists may not be reliable). Yet, the numbers are too small to reliably compare academics in each of these disciplines.

\section{Regression Models}

We examine the impact of several structural, demographic, and relational factors on several categories of experiences captured by the survey and confirmed by the Principal Components Analysis. The purpose of the regression analysis is to determine if there is a relationship between the experiential measures (i.e., aggression/neglect, department climate, legitimacy and affirmation, and material support and resources) and each of the structural variables (including $\mathrm{PhD}$ Year, $\mathrm{PhD}$ institution, current institution, discipline), a human capital variable (publications) a social capital variable (participation in race and ethnicity oriented organizations) and demographic variables (race, ethnicity, and gender) when the others are held constant. The findings, along with the open-ended interviews suggest what characteristics and relationships require changes to maintain diversity and to sustain it. We use the language of relationships because there is not necessarily a causal sequence between any given independent variable and any specific faculty experiences. For example, while obtaining a $\mathrm{PhD}$ at a research extensive institution probably predates faculty experiences, so it may be considered a causal variable. In contrast, belonging to a minority section or organization may be a response to negative experiences as well as an antecedent. 


\subsection{Basic Regression Models}

The basic model for these analyses is as follows:

Composite Measure (URM faculty experiences) $=\beta_{0}+\beta_{1}$ Average Publications Per Year + $\beta_{2}$ Graduated from $R E+\beta_{3}$ Years in Academia $+\beta_{4}$ Race $+\beta_{5}$ Sex $+\beta_{6}$ Discipline + $\beta_{7}$ Employed at $R E+\beta_{8}$ Minority Section $+e$

Although three out of four of the models were statistically significant (i.e., model 1 (aggression/neglect); model 2 (department and institutional climate), and model 4 (material support and resources), the explanatory power suggested by their respective r-squares is limited-explaining, at most, 12 percent of the variance in the composite measures of URM faculty experiences (see Table 4 below) (Furthermore, collinearity (VIF and Tolerance) statistics and Pearson's correlation matrices on variables in the models were assessed as a part of model reliability measures. Multicollinearity among variables in the model was not found). Table 4 shows that in models 1 and 4 , except for gender, structural, human capital, and social capital variables are not statistically significant at conventional levels. The exception is Model 2 (climate) in which gender is not significant, but two structural variables (graduated from a Research Institution and discipline) are positive and significant, when other variables are held constant.

Table 4. Multiple OLS regression coefficients for four URM faculty experiences.

\begin{tabular}{ccccc}
\hline & Aggression/Neglect & Climate & Legitimacy/Affirmation & Support/Resources \\
\hline Variable & Model 1 & Model 2 & Model 3 & Model 4 \\
\hline Avg. pubs per year & -0.617 & -0.341 & 1.162 & 1.253 \\
Graduated from RE & 3.418 & $2.776^{*}$ & 2.522 & 1.239 \\
Years in academia & 0.043 & -0.168 & 0.000 & 0.041 \\
Race (1 = Black) & 0.293 & 0.080 & 0.130 & 0.109 \\
Sex (1 = Female) & $-2.727^{* *}$ & -1.090 & -1.349 & $-1.335^{* *}$ \\
Discipline (1 = Sociology) & -1.958 & $-1.776^{*}$ & -2.047 & -0.555 \\
Employed at RE & 0.348 & -1.333 & -1.866 & 0.671 \\
Minority Section (1 = Yes) & -0.668 & -0.265 & -0.297 & -0.157 \\
Constant & 24.603 & 17.141 & 27.310 & 8.117 \\
Number of cases & 177 & 179 & 177 & 180 \\
R-Square & 0.107 & 0.099 & 0.064 & 0.122 \\
Cronbach Alpha & 0.922 & 0.931 & 0.885 & 0.825 \\
\hline
\end{tabular}

${ }^{*}=p<0.05 ;^{* *}=p<0.01$.

Model 1. While Model 1 examines if URM faculty experience aggression and/or neglect, the only statistically significant independent variable in the model is "female." That is significant and negative. This is further support for hypothesis 1 that URM women experience worse conditions than URM men. The coefficients show that women URM faculty are almost three times more likely to report experiencing aggression and/or neglect within their departments than their male colleagues, suggesting gender bias needs to be overcome if diversity is to be sustained. Approaching conventional statistical significance (Significance is determined at a $p$-value $<0.05)$ was faculty's "discipline" $(p=0.075)$, reinforcing the possibility of negative experiences being more likely in a sociology rather than an economics department. This finding may be the result of greater awareness of gender inequality in sociology departments where this issue is a major topic of analysis and conversation (although this is based on examination of graduate school curricula and not based on empirical studies). However, while not statistically significant in the model at conventional levels, this lack of significance in other variables could be a result of small sample sizes or the limitations of our survey and sample size to accurately capture the differences between the disciplines or the genders.

Model 2. Model 2 is statistically significant in explaining the variance in URM faculty responses to questions concerning departmental and institutional climate. Being female is 
not statistically significant at conventional levels. The only other statistically significant variables in the model are structural, i.e., "discipline" and, the institution type from which faculty obtained their PhD. The model suggests that URM faculty in sociology departments are almost twice as likely to report negative departmental and negative institutional climates as economists. In addition, those who received their $\mathrm{PhD}$ from research-extensive institutions were almost three times more likely to report positive departmental climates in their current departments. This positive evaluation is no longer the case as faculty members evaluate their current departments at research extensive departments. It is not clear why attending a research extensive institution as a graduate student results in a more positive evaluation of one's current department than does actual participation in the current departments. Perhaps the negative evaluation is because the road to gaining tenure is more fraught and more competitive, with less mentoring advice than the road to gaining a PhD at research extensive institutions and the road to sustaining diversity becomes less likely after graduate school as a result. Thus hypothesis 2 has limited support concerning the positive relations between institutional characteristics and negative experiences.

Model 3. Model 3 did not reach statistical significance. Therefore, it does not explain the variance in the experiences of legitimacy and affirmation among URM scholars and does not give us statistical hints for maintaining diversity. Being female is not significant. The only variable nearing statistical significance was discipline $(p=0.085)$, with economists claiming to experience more legitimacy and affirmation than sociologists. Again, this is a surprising finding and does not give us hints as to how to sustain diversity. This model does not, in general, support the hypothesis that structural conditions are related to experiences,

Model 4. As with Model 1, the only statistically significant variable at conventional levels in Model 4 was "sex" (female). The coefficient is negative suggesting that the women URM faculty in our sample are more likely to report a lack of material support and resources than their URM male colleagues, other things being equal. This finding suggests that the long history of women of color's secondary status when compared to men of color appears to be reflected in their current experiences. Nearing statistical significance and positively associated with receiving material support and resources was the average amount of publications per year by URM scholars $(p=0.094)$. This finding is not surprising. It suggests that the more one publishes, the more resources and material support may be allocated to individual faculty, although women may still gain fewer resources even when they publish more.

\subsection{Interaction Effects}

The main effects modeled in the linear regression did not find that belonging to a minority section significantly impacted URM faculty well-being and could aid in sustaining diversity in institutions of higher education. Therefore, the findings do not support hypothesis 3 . Nonetheless, we suspected that this relationship between minority section membership and various aspects of URM well-being may be dependent on gender, since our previous research suggested that more women than men participated in these organizations [46]. (This hypothesis was based from feedback from conference presentations and in-depth interviews. Our previous research found that except for participating in URM-oriented sections in sociology, URM-oriented organizations and activities did not have a positive relationship with academic mobility). Thus, in addition to estimating the main effects, we were also interested in the mediating effects between belonging to a minority section and being a woman URM faculty member. Hypothesis 4 posited that belonging to a minority section and being a woman in our model would have an impact on our four measures of well-being (Table 5). 
Table 5. Multiple OLS regression coefficients of URM faculty experience with Interaction between minority organization and Sex.

\begin{tabular}{ccccc}
\hline & Aggression/Neglect & Climate & Legitimacy/Affirmation & Support/Resources \\
\hline Variable & Model 1 & Model 2 & Model 3 & Model 4 \\
\hline Avg. pubs per year & -0.466 & -0.107 & 1.605 & 1.405 \\
Graduated from RE & 3.204 & 2.437 & 1.912 & 1.055 \\
Years in academia & 0.040 & -0.168 & 0.006 & 0.041 \\
Race (1 = Black) & 0.444 & 0.308 & 0.517 & 0.244 \\
Sex (1 = Female) & $-3.482 *$ & $-2.276^{*}$ & $-3.294^{*}$ & $-1.999 *$ \\
Discipline (1 = Sociology) & -1.854 & $-1.621^{*}$ & -1.755 & -0.447 \\
Employed at RE & 0.283 & $-1.485^{*}$ & $-2.113^{*}$ & 0.592 \\
Minority Section (1 = Yes) & -1.798 & -1.973 & -3.143 & -1.146 \\
Sex x Minority Section & -1.798 & $3.269 *$ & $5.301^{*}$ & 1.836 \\
Constant & 24.981 & 17.725 & 28.098 & 177 \\
Number of cases & 177 & 179 & 0.098 & 180 \\
R-Square & 0.113 & 0.125 & 0.138 \\
\hline
\end{tabular}

${ }^{*}=p<0.05 ;{ }^{* *}=p<0.01$.

When the interaction variable between sex and participation in a minority section is included in the models, the variable becomes statistically significant and negatively related to department climate, as well as to legitimacy and affirmation. Specifically, when the joint effect of sex and minority academic organization membership are considered, being female becomes significant, though negative in all four models. This finding does not suggest support for hypothesis 4 that women's participation in URM organizations improves women's experiences. Thus, is appears that URM men are more likely to benefit from participation in these networks, while URM women are significantly less likely to do so. For women participation in minority organization does not improve their experiences of aggression and neglect, and an increased sense of legitimacy in departments. Perhaps, we should expect it to, given that these organizations are not within departments. In sum, our data suggests that for some experiences, the relative sense of equality garnered from belonging to a minority section may depend on the gender of the URM faculty member but does not appear to sustain diversity for URM women.

\section{Conclusions and Policies to Sustain Diversity and Equality}

Within the historical context of marginality in institutions and organizations including the academic world, this paper asks whether URM women scholars' long history as public intellectuals and activists seems to have helped to overcome current unequal treatment in sociology and economics departments. We find that throughout a more than one-hundredyear history, women of color continue to have problems of access, marginality, inclusion, and harassment in patriarchal institutions, and efforts to increase equality and diversity may not be sustainable [3]. We hypothesized that women of color have significantly more negative experiences in sociology and economics departments than men of color that some structural variables may be an intervening condition, and that participation in organizations designed for scholars of color in sociology and economics would temper some of their negative experiences. Hypothesis 1 concerning unequal treatment of URM women in sociology and economics departments is supported by the findings. Hypothesis 2 tests whether structural conditions affect positive experiences is partially supported by the findings. Hypothesis 3 and 4 are not supported by the findings. Hypothesis 4 findings suggest another way that URM women are discriminated against. In short, we find that URM women appear to be treated unequally and have worse experiences than their male colleagues.

Their survey responses indicate that women respondents do not believe that they have equal resources, equal voice, experience more aggression and neglect, are less likely to be perceived as a legitimate scholar, and experience more harassment and extra scrutiny. These experiences are a current version of the exclusion, lack of voice, lack of legitimacy, 
and secondary status endured by women of color for more than one hundred years. They suggest the difficulty of sustaining equality and diversity with academic departments, specifically sociology and economics. These findings follow those of other researchers'. For example, a recent study [47] report women of color faculty were the least likely to believe that their research was valued by colleagues, citing a lack of respect from colleagues for their intellectual interests and/or research agendas. The pressure URM faculty feel to constantly "justify their existence" to their colleagues can foster a workplace environment where microaggressions are supported by the "chilly" institutional climate towards URM faculty and their work, especially at predominately White Institutions.

In the regression analyses finds that in two out of four sub-models of models1, that is aggression-neglect, and resources, being female is a negative and statistically significant variable The relationship between gender and negative experiences in these two models contrasts to the lack of significance (at conventional levels) of most of the structural variables in most of the sub-models, when we control for gender. These finding suggests that being a woman of color has fewer rewards than being a man of color, when other variables are held constant. In none of the models is participation in academic organizations focusing on people of color significant., However, when being female is interacted with organizational participation, we find that these interactive variables are negative and statistically significant, possible suggesting the participation in disciplinary organizations provide men but not women with a place to overcome departmental inequalities and help sustain diversity.

In conclusion, assuming the models are valid and reliable despite the small sample sizes, the results suggest that for women of color, publishing, years in the academy, graduating from and employment at a research-extensive institution, and discipline tend not to be significantly related (at conventional levels) to experiences of aggression and resources. In these two models, it appears that being female is the main explanation for URM women faculty's negative experiences and that women's experiences in sociology and economics may need to be more positive if diversity is to be sustained over time.

Despite inequalities between URM men and women, women of color continue to organize and develop organizations for URMs, as they have done historically, all the while producing an important body of literature including new paradigms centered on the experiences and epistemologies of women (and men) of color [2]. It is important to acknowledge the work of women of color as public intellectuals, ensuring diversity, founding social movements and organizations, public speaking, and writing.

Along with acknowledging their historic work, academic institutions must endeavor to improve their conditions to sustain diversity. A variety of initiatives could help to overcome gender and race inequalities such as continuing to recruit and promote women of color, developing better measures to evaluate their activities, giving credit for the extra service work they do, providing family policies, and providing more funding to women to complete their research and to participate in regional and annual meetings. Such policies can aid in making equality and diversity sustainable. In the short-term inclusive hiring must also take place within a context of a critical reexamination of existing institutional practices, norms, and procedures otherwise hiring policies will simply reproduce the structure of inequality in higher educational institutions.

\section{Recommendations}

These recommendations are drawn from the suggestions provided by during in-depth interviews with URM faculty in the sample:

\subsection{Diversity Initiatives}

First and foremost, departments and universities need more scholars of color (especially women) to teach and conduct research. Diversity initiatives by departments should not only increase the pool of URM scholars, but also strengthen the disciplines through inclusion, such as by adding multiple standpoints (10). Increasing diversity may require a 
series of strategies including bringing more URMs onto hiring and promotion committees and admission panels, even if this means using disciplinary outsiders, and to define areas of scholarship that will attract URMs. Faculty of color provided several instructive examples in this regard:

So graduate admissions are another place where if you want a diverse set of admits you know that you need people on the committee who will think outside the box in terms of what we're looking for or that the, you know, the applicant characteristics that we pay attention to or qualifications.

I think as a selling point to the school and the university to get them to go along with [Africana Studies] we were able to point out that the universities with better records on their recruitment and retention of URM faculty had departments because those departments usually do provide a more welcoming space for faculty and for students and provides a space for the you know the sort of the kinds of work that often are more difficult fits in traditional academic departments.

We've also formally established areas of research where underrepresented minority scholars are most likely to be active ... So by having those formal explicitly recognized areas of scholarship it should be easier to attract underrepresented minority scholars here because the areas that they may want to work on are ones that we kind of actively reflect and support in our ... departmental programming materials and our departmental formal departmental structure.

\subsection{Evaluation}

Second, to increase and maintain diversity, departments should develop better evaluation measures. While tenure evaluations continue to emphasize publishing in peer-reviewed journals as the sole measure of faculty productivity, this can have detrimental effects on URM faculty who are essentially performing a "second shift" in their departments:

There were certain things that were expected of me that are not expected of my White colleagues ... they were expectations of me ... to reach out through racial ethnic minorities. Right. But the thing, that expectation, for women was not the case for my White colleagues who the majority are White male.

There's more sort of informal service because you advise all of the students of color whether they're assigned to you or not whether you're on their committees or not ... I mean there's just a lot of emotional work that isn't. You know that's not anything I would ever put on my activity report it's not going to contribute to my getting a raise or anything.

In response, departments should develop better and more inclusive and holistic evaluation measures that add service and teaching to the powerful 'publish or perish' paradigm or perhaps identify a broader set of peer-reviewed journals than the top in the field. While URM faculty continue to be underrepresented and continue do more service work, the narrow measure of productivity can disadvantage URM faculty in the promotion process, and thus, can further contribute to the "leaky pipeline". To correct for this, interviewees gave several practical suggestions that include lightening the amount of service performed by junior faculty by shifting the responsibility to tenured faculty, course reductions and providing more resources to junior faculty in the form of research and teaching assistants.

\subsection{Family Policies}

Third, creation and enforcement of work/family policies could level the playing field for women (including women of color) such as extension of the tenure clock or flexible schedules for new parents or those caring for the elderly. Women note the strain of work responsibilities on family and the lack of support [48,49] (While men do not report the same family/work challenges, some do recognize the added strain placed on women. One male faculty member noted:

I have to say that there were people who are really supportive about having kids. I don't know what it would have been like if I were a woman though. I'd like to think in our department that I would get the same treatment ... We haven't had a junior professor a junior faculty in our department who is a woman have a baby probably in decades. 


\subsection{Disciplinary Association Policy}

Not all changes can be made by departments; disciplinary associations have a role to play. First, they should apply for more funds to send women of color to disciplinary meetings and to programs for URM Scholars, so they can find a safe space to present their work, meet possible collaborators and mentors, and increase their sense of legitimacy [48]. Several sociologist and economist interviewees attributed a sense of well-being to their participation in these organizations:

I think [the organizations] have been helpful to me as a scholar for a couple reasons. One, I think mentorship has been very helpful kind of network, advice... I just also think when you're in a situation where you're the only underrepresented minority, it's nice to have a connection to people at least in the broader profession that are also underrepresented minorities.

... if somebody were a junior person and they were looking for kind of a home and they were a minority or looking at minority issues and they were asking me how can I kind of get settled in and find people and get connected? Then I would definitely feel confident saying you know consider joining the section and going to the business meeting and stuff like that ... my sense is that they do provide that sort of safe space.

For those who attend disciplinary meetings, more effort should be made to keep panels diverse and ensure that women of colors' work are visible. For example:

The main thing is [NEA] provides an automatic set of colleagues. You know which people aren't going to find in any Econ department usually. And I just think that it's because the programs that we have to keep growing them.

So, I was in the AEA summer program before I started my Ph.D. I was in the pipeline program and I had a mentor when I was in a Ph.D. program and that was like a lifeline. It made my progression through the Ph.D. a lot easier to have that kind of mentorship and support. I have also been in the DITE program as well. And so that was helpful in terms of just understanding sort of the tenure process and so.

I think ASA would benefit if they took it upon themselves, a policy that said OK you know your panel your presentations should be diverse by gender by race ethnicity. Sometimes you go to the ASA and its a whole panel of one particular group. And it might because they have similar research interests but that they should make every effort or intention to diversify their panel.

Another policy to increase and sustain diversity is to create more systematic mentoring programs for early and mid-career faculty at both departments and disciplines.

I think what needs to happen is that first of all we need to mentor more underrepresented minority faculty right. We need to cultivate strong trusting mentorship relationships with the young, build a bridge with young and old scholars together.

All of these policies are designed to increase the numbers of women (and men) who have satisfactory academic careers. While there are a substantially higher percentage of URM women faculty in sociology than in economics, yet having a greater proportion of women in a discipline does not necessarily mean the end of bias and harassment. The issue of sexual harassment has come to the forefront in both disciplines. As suggested by the National Academy's Report on Sexual Harassment [22] ( disciplines should serve as places to report incidents of aggression as well as ensuring that women can participate in the discipline without fear of a negative climate.

\section{Overcoming Problems in Future Research}

A future version of this research should with White men and White women in the academy. This comparison would allow us to be sure if White women also experienced the same kinds of discrimination and at the same rates as women of color. Future research should expand to broaden the notion of intersectionality. By examining the experiences of White men and women, the analysis would include those who tend not to be oppressed or discriminated against (white men) and those who are in one oppressed category, but not in the other (white women).

Next, a data base with greater validity in testing hypotheses would include those URM faculty of dropped out because they did not obtain tenure or because they felt demeaned or 
socially isolated. There again, this would require a lengthy and difficult effort with much missing data.

An additional problem that should be overcome in future research is that of participation in minority organizations. In this paper we only include membership and not participation, e.g., being an officer or board member of the organization. This information can be amassed with difficulty, but could be done.

We suggest additional research should be conducted to learn more about different kinds of participation in URM organizations and mentoring programs. We hope that further survey research would include larger sample sizes and explicitly target participation in URM organizations to explicate these relationships in greater depth. Addition of a White sample might also prove to increase our understanding of racial dynamics. Finally, moving beyond sociology and economics departments would allow university administrators to understand the scope and depth of obstacles across disciplines. Although, based on our experiences, relatively few disciplines collect the data that would allow such comparisons.

Funding: National Science Foundation grant 1421090, titled "Science of Broadening Participation: Stratification in Academic Career Trajectories".

Institutional Review Board Statement: The American Sociological Association does not have an institutional review board, but we consulted with John Kennedy, the head of the Institutional Review Board at Indiana University.

Informed Consent Statement: Informed consent was obtained by all respondents.

Data Availability Statement: These data are currently not publicly available.

Conflicts of Interest: The author declares not conflict of interest.

\section{Appendix A}

Table A1. Coding Scheme: Categories and Sub-Categories of Experience.

\begin{tabular}{l} 
Theme \\
\hline Left out of non-work activities. \\
Verbal abuse, ridicule, slander, non-academic based. \\
Being ignored when attempting to outreach. \\
Scrutiny and ridicule of scholar work, academic based. \\
Appearance ridicule. \\
Climate focus on whole (department or school). \\
URM faculty are recruited equally. \\
URM faculty are equally judged in tenure and promotion. \\
URM receive career advice and support for their work/mentorship. \\
URM receive career advice and support for their work/mentorship \\
(5) URM have influence in department decisions \\
\hline Legitimacy is singular focus (sense of self, "me") \\
Faculty are valued for teaching, research, and service. \\
Sense of more than coworkers. \\
Able to collaborate or ask for help with problems. \\
There is interaction and influence in department decisions. \\
Faculty are given the means to achieve in their position. This entails \\
resources to carry out research (funding, equipment, \\
software, students). \\
Compensation, whether it be salary or other benefits, is equal to \\
those in the field and matches faculty's efforts. \\
Material resources are enough that it allows a balance between life, \\
work, and service obligations.
\end{tabular}


Table A2. Total Variance Explained in Survey Responses by PCA.

\begin{tabular}{|c|c|c|c|c|c|c|c|}
\hline \multirow[b]{2}{*}{ Component } & \multirow[b]{2}{*}{$N$} & \multirow[b]{2}{*}{ Mean (SD) } & \multirow[b]{2}{*}{ Minimum } & \multicolumn{3}{|c|}{ Initial Eigenvalues } & \multirow[b]{2}{*}{ Cumulative $\%$} \\
\hline & & & & Maximum & Total & $\%$ of Variance & \\
\hline 1. Aggression/Neglect & 189 & $25.21(6.35)$ & 8.00 & 32.00 & 12.78 & 49.149 & 49.149 \\
\hline 2. Departmental/Institutional Climate & 191 & $14.52(4.72)$ & 5.00 & 20.00 & 2.12 & 8.139 & 57.288 \\
\hline 3. Legitimacy/Affirmation & 190 & $27.71(6.71)$ & 9.00 & 36.00 & 1.58 & 6.088 & 63.375 \\
\hline 4. Material Support/Resources & 192 & $10.23(3.39)$ & 4.00 & 16.00 & 1.23 & 4.726 & 68.102 \\
\hline
\end{tabular}

$\mathrm{KMO}=0.935$; Bartlett's test of sphericity $\left(\chi^{2}(182)=3599.08, p<0.0005\right)$.

\section{References}

1. Bonilla-Silva, E. What We Were, What We Are, and What We Should Be: The Racial Problem of American Sociology. Soc. Probl. 2017, 64, 179-187. [CrossRef]

2. Cooper, B.C. Beyond Respectability: The Intellectual Thought of Race Women; University of Illinois Press: Urbana, IL, USA, 2017.

3. Moore, M.R. Women of Color in the Academy: Navigating Multiple Intersections and Multiple Hierarchies. Social. Problems. 2017, 61, 200-205. [CrossRef]

4. Collins, P.H. Black Feminist Thought and the Matrix of Domination. In Black Feminist Thought: Knowledge, Consciousness, and the Politics of Empowerment; Collins, P.H., Ed.; Unwin Hyman: Boston, MA, USA, 1990.

5. Brewer, R.M. Black Women and Feminist Sociology: The Emerging Prospective. Am. Sociologist. 1989, 20, 57-70. [CrossRef]

6. Collins, P.H. Learning from the Outsider Within. Social. Probl. 1986, 33, S14-S32. [CrossRef]

7. Collins, P.H.; Bilge, S. Intersectionality (Key Concepts); Polity Press: Cambridge, UK, 2016.

8. Crenshaw, K. Demarginalizing the Intersection of Race and Sex: A Black Feminist Critique of Antidiscrimination Doctrine, Feminist Theory and Antiracist Politics. Univ. Chic. Leg. Forum 1989, 8. Available online: http://chicagounbound.uchicago.edu/ uclf/vol1989/iss1/8 (accessed on 10 April 2021).

9. Smith, B. Racism and Women's Studies. In All the Women are White, All of the Blacks are Men, But Some of Us are Brave: Black Women's Studies, 2nd ed.; Hull, A., Scott, P.H., Smith, B., Eds.; Feminist Press: New York, NY, USA, 1982; pp. 48-52.

10. Few, A.L. Integrating Black Consciousness and Critical Race Feminism into Family Studies Research. J. Family Issues 2007, 28, 452-473. [CrossRef]

11. Giddings, P. When and Where I Enter.: The Impact of Black Women on Race and Sex in America; Bantam Books: New York, NY, USA, 1985.

12. Hurtado, A. The Color of Privilege: Three Blasphemies on Race and Feminism; University of Michigan Press: Ann Arbor, MI, USA, 1996.

13. Wright, E.W., II. The First American School of Sociology; Routledge: New York, NY, USA, 2016.

14. Wright, W., II; Wallace, E.V. The Ashgate Research Companion to Black Sociology; Routledge: New York, NY, USA, 2015.

15. Morris, A. The Scholar Denied; University of California Press: Oakland, CA, USA, 2016.

16. Cavalieri, M. Inside Institutions of Progressive-Era Social Sciences: The Interdisciplinarity of Economics and Sociology. J. Econ. Issues 2016, 50, 345-361. [CrossRef]

17. Young, C. The Emergence of Sociology from Political Economy in the United States: 1890 to 1940. J. Hist. Behav. Sci. 2009, 45, 91-116. [CrossRef] [PubMed]

18. Forget, E. Women of Value: Feminist Essays on the History of Women in Economics. Econ. J. 1996. [CrossRef]

19. Welter, B. The Cult of True Womanhood: 1820-1860. Am. Q. 1966, 18, 161-174. [CrossRef]

20. Darity, W., Jr.; Hamilton, D.; Mason, P.L.; Price, G.N.; Dávila, A.; Mora, M.T.; Stockley, S.K. Stratification Economics: A General Theory of Intergroup Inequality. In The Hidden Rules of Race: Barriers to an Inclusive Economy; NY Cambridge University Press: New York, NY, USA; Available online: https:/ / www.cambridge.org/ (accessed on 10 April 2021).

21. National Science Foundation. National Center for Science and Engineering Statistics. Directorate for the Behavioral and Economic Sciences. Survey of Earned Doctorates. S\&E Degrees Awarded by Degree Level. Available online: https://www.nsf.gov/ statistics/srvydoctorates/ (accessed on 10 April 2021).

22. $\mathrm{Wu}, \mathrm{A} . \mathrm{H}$. Gender Stereotyping in Academia: Evidence from Economics Job Market Rumors Forum. American Economics Assocition. Available online: https://growthecon.com/assets/Wu_EJMR_paper.pdf (accessed on 10 April 2021).

23. National Academies of Sciences, Engineering, and Medicine. Sexual Harassment of Women: Climate, Culture, and Consequences in Academic Sciences, Engineering, and Medicine; The National Academies Press: Washington, DC, USA, 2018. [CrossRef]

24. Alfred, M.V. Sisters of the Academy: Emergent Black Women Scholars in Higher Education; Mabokela, R.O., Green, A.L., Eds.; Stylus Publishing: Sterling, VA, USA, 2001; pp. 57-79.

25. Cotera, M.P. The Chicana Feminist. Information Systems Development; Information Systems Development: Austin, TX, USA, 1977.

26. De la Torre, A.; Pesquera, B. Introduction. In Building with Our Hands: New Directions in Chicana Studies; University of California Press: Berkeley, CA, USA, 1993; pp. 1-15.

27. Luziris, T. In Between La Maliche and Gloria Anzaldua: Feminism of Mexican and Mexican American Women in the United States, 1910-1950. Plaza Dialogues Lang. Lit. 2011, 1.

28. Higgenbothom, E. Black Professional Women: Job Ceilings and Employment Sectors. In Women of Color in the U.S.; Temple University Press: Philadelphia, PA, USA, 1994; pp. 113-131. 
29. Lewis, D. A Response to Inequality: Black Women, Racism and Sexism. In Black Women In America: Social Science Perspectives; Malson, M., Mudimbe-Boyi, E., O’Barr, J.F., Mary, Eds.; University of Chicago Press: Chicago, IL, USA, 1990; pp. 41-64.

30. Zavella, P. The Problematic Relationship between Feminism and Chicana Studies. Women's Stud. 1988, 17, 123-134.

31. Mullings, L. On Our Own Terms; Routledge: New York, NY, USA, 1997.

32. Roth, B. Separate Roads to Feminism: Black, Chicana, and White Feminist Movements in America's Second Wave; Cambridge University Press: New York, NY, USA, 2004.

33. Mirande, A.; Enriquez, E. The Chicana: The Mexican American Woman; University of Chicago Press: Chicago, IL, USA, 1978.

34. Segura, D.A. Review Essay: Challenging the Chicano Text: Toward a More Inclusive Contemporary Causa. SIGNS J. Women Cult. 2001, 26, 541-550. [CrossRef]

35. Mirande, A. Que Gacho es ser Macho: It's a Drag to be a Macho Man. Aztalan 1988, 17, 63-89.

36. Regua, N. Women in the Chicano Movement. Women's Stud. 2012, 12, 114-142.

37. Segura, D.A.; Pesquera, B.M. Chicana Political Consciousness: Renegotiating Culture, Class and Gender with Oppositional Practices. Aztlán A J. Chicano Stud. 1999, 24, 1-32.

38. Arrendado, G.; Hurtado, A.; Klahn, N.; Najera-Ramirez, O.; Zavella, P. Chicana Feminisms: A Critical Reader; Duke University Press Books: Durham, NC, USA, 2003.

39. Segura, D.A. Ambivalence or Continuity: Motherhood and Employment Among Chicanas and Mexican Immigrant Women. Aztlán A J. Chicano Stud. 1991, 20, 119-150.

40. Del Castillo, A. Between Borders: Essays on Mexican/Chicana History; Floricanto Press: Encino, CA, USA, 1990.

41. Gandara, P. Over the Ivy Wall: The Educational Mobility of Low-Income Chicanas; University of Albany Press: Albany, NY, USA, 1885.

42. Leggon, C. African American Faculty in Science and Engineering: The Illusion of Inclusion. In Beyond Stock Stories and Folktales: African Americans' Paths to STEM Fields (Diversity in Higher Education, Vol. 11); Emerald Group Publishing Limited: Bingley, UK, 2011; pp. 273-286.

43. Price, G.; Sharpe, R. Black Economist Hiring Report Card for Ph.D. Granting Economics Departments: 2014-2015. Available online: https://www.researchgate.net/publication/313377635_Black_Economist_Hiring_Report_Card_For_PhD_Granting_ Economics_Departments_2014_-_2015 (accessed on 10 April 2021).

44. Bourdieu, P.l.; Wacquant, L.J.D. An Invitation to Reflexive Sociology; University of Chicago Press: Chicago, IL, USA, 2008.

45. Reskin, B.; Roos, P. Job Queues, Gender Queues: Explaining Women's Inroads into Male Occupations; Temple University Press: Philadelphia, PA, USA, 2009.

46. Castaneda, M.; Zambrana, R.E.; Marsh, K.; Vega, W.; Becerra, R.; Perez, D.J. Role of Institutional Climate on Underrepresented Faculty Perceptions and DecisionMaking in Use of Work-Family Policies. Fam. Relat. 2015, 64, 711-725. [CrossRef]

47. Spalter-Roth, R.; Shin, J.; Smith, J.; Kalb, A. "Raced" Organizations and the Academic Success of Underrepresented Minority Faculty Members in Sociology. Sociol. Race Ethn. 2018. [CrossRef]

48. Spalter-Roth, R.; Kennelly, I. The Best Time to Have a Baby: Institutional Resources and Family Strategies among Early Career Sociologists. Am. Sociol. 2004, 4, 29-49.

49. Ward, K.; Wolfe-Wendel, L. Academic Life and Motherhood: Variation by Institution Type. In Proceedings of the Paper presented at Roundtable in Faculty Work/Family Issues, American Association of University Professors and the Alfred P. Sloan Foundation, Washington, DC, USA, 14-15 July 2003. 